\title{
FULL REFERENCE:
}

Rodríguez-Déniz, H.; Suau-Sanchez, P.; Voltes-Dorta, A. (2013): “Classifying airports according to their hub dimensions: An application to the US domestic network". Journal of Transport Geography 33, 188-195

http://dx.doi.org/10.1016/j.jtrangeo.2013.10.011

Classifying airports according to their hub dimensions: An application to the US domestic network

Héctor RODRÍGUEZ-DÉNIZ ${ }^{1}$, Pere SUAU-SANCHEZ ${ }^{2 *}$, Augusto VOLTES-DORTA ${ }^{3}$

${ }^{1}$ Héctor RODRÍGUEZ-DÉNIZ

Universidad de Las Palmas de Gran Canaria, FCEE. D.3.01, 35017 Las Palmas de Gran

Canaria, Spain.

E-mail: hrodriguez@becarios.ulpgc.es

Tel.: +34928458212

${ }^{2}$ Pere SUAU-SANCHEZ

Centre for Air Transport Management, Martell House, Cranfield University, Bedfordshire MK43 0TR, United Kingdom

E-mail: p.suausanchez@cranfield.ac.uk

Tel.: +44 1234754227

${ }^{3}$ Augusto VOLTES-DORTA

Management Science and Business Economics Group, University of Edinburgh Business School, Edinburgh EH8 9JS, United Kingdom

E-mail: avoltes@becarios.ulpgc.es

* Corresponding author: Pere SUAU-SANCHEZ

Centre for Air Transport Management, Martell House, Cranfield University, Bedfordshire MK43 0TR, United Kingdom

E-mail: p.suausanchez@cranfield.ac.uk 


\section{Classifying airports according to their hub dimensions: An application to the US domestic network}

\section{Introduction}

The US Federal Aviation Administration (FAA) estimates that $\$ 42.5$ billion will be available over the period 2013-2017 to fund infrastructure developments for all segments of civil aviation under the Airport Improvement Program (AIP). The National Plan of Integrated Airport Systems (NPIAS) is used by the FAA in administering the AIP. In the NPIAS (FAA, 2011), investment requirements and funding priorities are set according to an airport typology based on each airport's traffic share over total US passenger enplanements (Table 1).

While the merit and simplicity of that approach are not questioned, the drastic changes in route structures after deregulation suggest that the importance of large airports is dependent on their ability to accommodate hub-and-spoke operations, which are typically achieved by consolidating originating and transfer passenger flows (Button, 2002; Doganis, 2010). These two dimensions of hubbing (traffic generation and connectivity) are not explicitly considered by the FAA in its current hub classification. In this paper, we firstly aim to check whether this leads to ambiguity when characterizing the hub nature of the airports in the NPIAS.

To that end, the second objective of the paper is the development of a demand-based indicator of airport connectivity, which we achieve by adapting the theory of flow centrality to an air transport context. This indicator measures the proportion of total network traffic that travels through an intermediate node. The suitability of our flow centrality indicator is assessed against other measures by testing their sensitivity to the major cases of airline dehubbing in the US, using quarterly data on domestic passenger demand between 1993 and 2012 .

Finally, the third goal is the definition of an alternative airport classification method, based on the two dimensions of hubbing, within the context of the NPIAS.

Table 1. Commercial airport categories according to FAA's current classification. Source: FAA.

\begin{tabular}{|l|l|l|}
\hline $\begin{array}{l}\text { Commercial Airport } \\
\text { Type } \\
\text { At least 2,500 boardings }\end{array}$ & $\begin{array}{l}\text { Hub type } \\
\text { Percentage of annual passenger } \\
\text { boardings }\end{array}$ & Common name \\
\hline \multirow{5}{*}{ Primary } & $\begin{array}{l}\text { Large } \\
1 \% \text { or more }\end{array}$ & Large Hub \\
\cline { 2 - 3 } & $\begin{array}{l}\text { Medium } \\
\text { At least } 0.25 \% \text {, but less than } 1 \%\end{array}$ & Medium Hub \\
\cline { 2 - 3 } & $\begin{array}{l}\text { Small } \\
\text { At least } 0.05 \% \text {, but less than } \\
0.25 \%\end{array}$ & Small Hub \\
\cline { 2 - 3 } & $\begin{array}{l}\text { Nonhub } \\
\text { More than } 10,000, \text { but less than }\end{array}$ & \\
\hline Nonprimary & $0.05 \%$ & Nonhub Primary \\
& $\begin{array}{l}\text { Nonhub } \\
\text { At least } 2,500 \text { and no more than } \\
10,000\end{array}$ & $\begin{array}{l}\text { Nonprimary Commercial } \\
\text { Service }\end{array}$ \\
\hline
\end{tabular}


The paper is structured as follows: Section 2 reviews airport classifications, connectivity and centrality indicators. Section 3 describes the data, and covers all methodological aspects, including the development of the flow centrality connectivity indicator. Section 4 discusses the benefits of classifying large airports according to their hub dimensions and an alternative classification of large US hubs is provided using hierarchical clustering techniques. Section 5 presents the conclusions.

\section{Airport classification, hub dimensions and connectivity}

\subsection{Airport classification}

Classifying airports into homogeneous groups is typically used for benchmarking purposes in both policy and management contexts. Previous literature on airport classification is very heterogeneous, although it seems to be a consensus that hierarchical clustering methods are the most commonly employed (Rodríguez-Déniz and Voltes-Dorta, 2014). These have been applied to a wide variety of subjects, ranging from accessibility and connectivity (Burghouwt and Hakfoort, 2001; Malighetti et al., 2009), runway geometry (Galle el al., 2010), slot allocation (Madas and Zografos, 2008), and the comparative analysis of efficiency and productivity (Sarkis and Talluri, 2004). The type of variables used to classify airports also varies widely, including traffic, infrastructure, and financial indicators (Jessop, 2012).

With regard to the US, the closest reference to the present paper is Adikariwattage et al. (2012). They classified US airports using four variables: number of boarding gates, number of origin and destination passengers, transfer and international passengers. They cluster airports in two steps, separating the number of gates from the passenger volumes leading to nine groups that combine all these variables. However, their results are not particularly sensitive for the largest hubs, since all of them are grouped together in the same category (e.g., JFK, LAX, ATL, and CLT), despite presenting radical differences in their hub profiles, as it is analysed in Section 4. We build on their contribution to produce a more sensitive method for classifying large hubs within the context of the NPIAS. We try to achieve this by focusing on the airports' relative contribution to the network in terms of both traffic generation and connectivity, rather than simply relying on absolute passenger volumes. These variables have not been explicitly used before to classify US airports.

\subsection{Hub dimensions, airport connectivity and centrality indicators}

Hub-and-spoke operations are typically achieved by consolidating originating and transfer passenger flows (Doganis, 2010; Button 2002), which implies the existence of two dimensions of hubbing: traffic generation and connectivity.

Connecting traffic is traffic between airport A and airport B via the hub airport $\mathrm{H}$. Effective hubbing generates substantial volumes of additional traffic at the hub airport. The city-pair coverage that can be obtained is significant, since increase in the number of airports served from the hub impacts exponentially on the number of city-pairs served (Doganis, 2010).

Generated traffic is traffic between hub airport $\mathrm{H}$ and airport A. Although we tend to focus on the importance of transfer traffic at hubs, these are still highly dependent on nontransfer traffic, since some flight sectors have important shares of non-transfer passengers 
and the increase of direct services can produce a multiplying effect on the generation of traffic from and to the hub. As a matter of fact, most hubs are located in regions with large local markets (Liu et al. 2006).

Concerning specifically airport hub classification and identification, it is difficult to find studies using both dimensions of airport hubbing (i.e., traffic generation and connectivity). Some connectivity measures ${ }^{1}$ are able to capture both dimensions. Yet, since they rely on supply data of seats and frequencies, connectivity indices usually focus on different aspects of potential connectivity, such as the number of feasible connections available to the passenger, and centrality indices evaluate the airport's hubbing potential on the basis of its central location in the network. This is related to the difficulties in collecting demand data on actual connections made by passengers.

The necessary information on actual passenger routings, however, was made available for the US domestic network by the Department of Transportation. This database includes a $10 \%$ sample of tickets sold; hence, it does not allow us to measure the total number of originating and connecting passengers at each airport, a priori the obvious indicators for traffic generation and connectivity. Alternatively, we adapt the well-known concept of flow centrality to an air transport context and develop two demand-based measures of the hubbing activity. Based on our flow centrality indicators, we define an alternative airport classification method with stronger hub discrimination power than the existing FAA airport classification.

\section{Data and methodology}

\subsection{Database}

As mentioned above, we use the publicly available data provided by the Bureau of Transportation Statistics of the Research and Innovative Technology Administration (US Department of Transportation). The Airline Origin and Destination Survey (Database code: DB1B) (RITA, 2013) is a sample of airline ticket information from more than 30 US carriers. The survey covers about $10 \%$ of domestic tickets sold by the reporting carriers with specific indication of the full itinerary for multi-sector journeys. Additional variables included in the dataset are the operating carrier, the number of passengers or the distance flown, among others. These records are available on a quarterly basis and were collected from the first quarter 1993 to the second quarter 2012 for our time-series analysis. The resulting sample contains about 350 million records representing individual itineraries.

It is worth clarifying that only domestic itineraries are included in this database (i.e., journeys with both origin and destination airports located in the US) and that there are not other free available databases providing information on the full itinerary of international passengers.

\footnotetext{
1 See Burghouwt and Redondi (2013) for an extensive review of these types of measures. These indicators can be roughly classified according to whether they consider temporal restrictions (to determine when an indirect connection is viable) or take into account all possible connections in the network (global versus local models). While the bulk of the literature is focused on time-dependent local measures (e.g., Doganis and Dennis, 1989; Dennis, 1994; Bootsma, 1997; Veldhuis, 1997; Burghouwt, 2007), there has been a growing interest on global models in the recent years (e.g., Guimerà et al., 2005; Malighetti et al., 2008; Xu and Harris, 2008; Paleari et al., 2010; Wang et al., 2011; Jia and Jiang, 2012). Global models are usually based on measures coming from complex network theory (e.g., Freeman, 1977, 1978), which is more computationally demanding.
} 


\subsection{Flow centrality}

In order to measure airport connectivity, this paper adapts the well-known flow centrality measure from Freeman et al. (1991). This indicator was developed in a social network context and aims to quantify the proportion of the maximum directed flow of information $(\mathrm{m})$ between two nodes $(j, k)$ that travels through an intermediate node $\left(x_{i}\right)$. This maximum flow will depend on the capacity of the links in the network and it is calculated for each pair of nodes by applying some simple rules, such as that incoming flow must equal outgoing flow for all nodes involved in the transmission of information. By aggregating all possible pairs of nodes $(j, k)$, the measurement of flow centrality for node $x_{i}$ is easily calculated as the total directed flow that passes through $x_{i}$ divided by the total flow between all pairs of nodes where $x_{i}$ is neither a source of information nor its final destination. Thus, the flow centrality (valued between 0 and 1) measures the proportion of the total network flow that travels through $x_{i}$.

$$
C_{F}^{\prime}\left(x_{i}\right)=\frac{\sum_{j<k}^{n} \sum_{k}^{n} m_{j k}\left(x_{i}\right)}{\sum_{j<k}^{n} \sum_{k}^{n} m_{j k}}
$$

Adapting this indicator to an air transport context is straightforward. Airports in the US domestic network are defined as nodes. The links that connect the nodes are the individual flight sectors operated by airlines. Passenger traffic is the flow that travels through the network between a point of origin $(j)$ and a final destination $(k)$ using a variety of routes (either non-stop of connecting). Note the market-based definition of passenger flow. The capacity of the links is defined by the total passengers from all different origin/destination markets that share the same individual sector. Since the available data provides information on origin, destination, and intermediate airports (when applicable) at a passenger level, it is possible to obtain both flow and capacity matrices. ${ }^{2}$ By incorporating all these definitions into the $C_{F}^{\prime}$ formula (1) and assuming that the maximum flow equals observed flow, the degree of flow centrality for airport $x_{i}$ collapses into a quotient between total number of passengers that connect through $x_{i}$ and total network passengers that travel in all markets that do not start or terminate at $x_{i}$. This ratio becomes our flow-based measure of connectivity. A numerical example is provided in Figure 1, where numbers denote passengers in each market meaning that the market between $Y$ and $Z$ airports comprises 5 passengers, 2 travelling nonstop and 3 via the hub $X$. Therefore, the value of flow centrality for airport $X$ is $3 / 5(0.6)$. In other words, the network has a $60 \%$ dependence on $X$ to serve the $Y$ - $Z$ market.

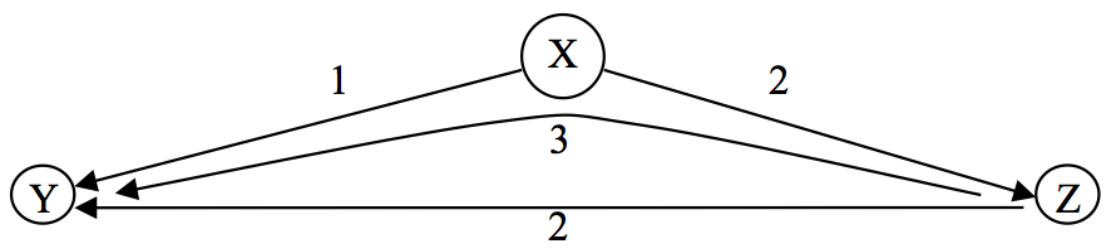

Figure 1. Numerical example of flow centrality.

\footnotetext{
${ }^{2}$ For itineraries with more than one stopover, passengers are assigned to all intermediate stops, regardless to whether the trip had a single or multiple flight numbers.
} 


\subsection{Benchmarking analysis}

The suitability of the demand-based flow centrality measure is tested by measuring its sensitivity to changes in airport connectivity during airline de-hubbing, when a dominating carrier dismantles its hubs activities in one of its main bases (Bhadra, 2009). Airline dehubbing implies a sudden change in connectivity; therefore, it should be a suitable event for performing the benchmarking. Redondi et al. (2012), doing a supply-based time-series analysis, identify up to 37 worldwide cases of de-hubbing from 1997 to 2009. Using their list, we apply four different centrality indicators (Degree Centrality [Degree], Weighted Betweenness Centrality [WBC], Un-weighted Betweenness Centrality [BC], and Flow Centrality $\left[\mathrm{C}_{\mathrm{i}}\right]$ ) for a selection of US airports that have suffered a de-hubbing process during the last decades.

Degree centrality (Nieminem, 1974) represents the number of connections that an airport has. It can be formalized for an airport $i$ as:

$$
C_{D}(i)=\sum_{j} \frac{A_{i j}+A_{j i}}{2}
$$

where $A_{i j}$ is the adjacency matrix, in which $A_{i j}=1$ if the airport $i$ is connected to airport $j$, and 0 otherwise.

Betweenness centrality (Freeman, 1977) quantifies the prominence of an actor within a network by computing how frequently a node lies on the shortest path between any other two nodes. The betweenness centrality measure is given by:

$$
C_{B}(v)=\sum_{s \neq v \neq t \in V} \frac{\sigma_{s t}(v)}{\sigma_{s t}}
$$

where $\sigma_{s t}$ is the number of minimum length paths connecting nodes $s \in V$ and $t \in V$, and $\sigma_{s t}(v)$ is the number of such paths in which some $v \in V$ lies on. Airports with high levels of betweenness will be in a privileged, central position in comparison with the rest of their peers. From an air transport perspective, however, the betweenness centrality presents some serious drawbacks due to its strong topological motivation. ${ }^{3}$ In order to overcome these limitations, Rodríguez-Déniz (2012) introduced a market-based betweenness centrality to identify central airports according to both their topological position (i.e., connectivity potential) and the relevance of the markets they serve in terms of traffic density, defined as:

$$
C_{B_{m k t}}(v)=\sum_{s \neq v \neq t \in V} \frac{Q_{s t}}{Q} \cdot \frac{\sigma_{s t}(v)}{\sigma_{s t}},
$$

where $\left(Q_{s t}\right)$ is the total number of passengers that travelled on market $s, t \in V$, and $(Q)$ the total number of passengers in the sample. As a result, top ranked airports are likely to play an important role within the network by combining a central location with relevant market service. Airports lacking of either characteristic will be penalized.

\subsection{An aggregated indicator for the hub dimensions}

After the benchmarking analysis, the flow centrality indicator will be used to develop an alternative airport typology. This is expected to be useful to classify large airports with a

\footnotetext{
${ }^{3}$ Airports that serve as gateways to isolated regions (e.g., Anchorage, Honolulu) score high on betweenness centrality. However, they could hardly be considered "central" to the US airport network.
} 
potential to serve connecting traffic. However, it is worth remembering that connectivity is only one of the two main dimensions of a hub, which should also generate a significant amount of traffic (either as origin or final destination). These two dimensions (connectivity and traffic generation) will become the variables of our proposed classification method.

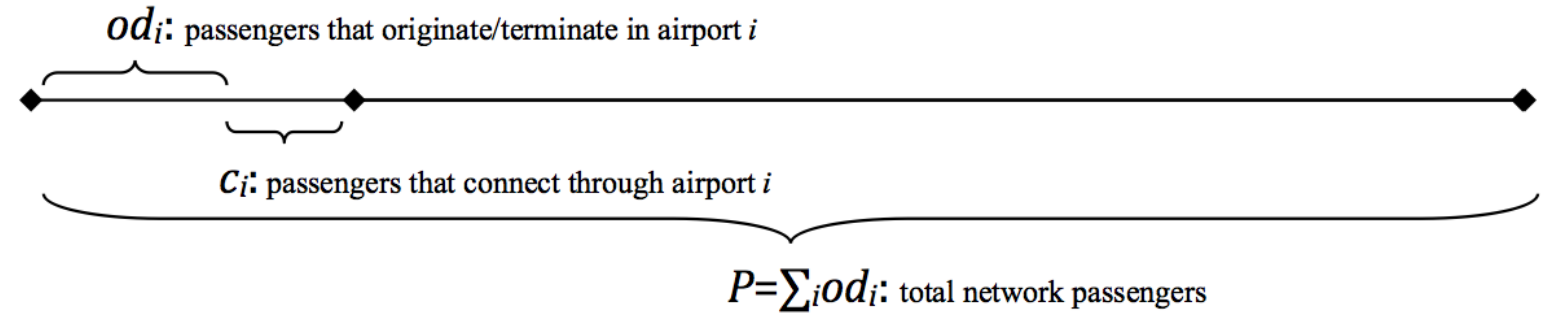

Figure 2. Partition of the total network flows with respect to airport $i$.

Following the simple nomenclature presented in Figure 2, we can easily define two separate measures for each airport's traffic contribution to the network. The first one $\left(O D_{i}\right)$ is calculated as the ratio between the passengers that originate or terminate at the airport $i\left(o d_{i}\right)$ and the total network passengers $(P)$. This serves as an indicator of the airport's importance as generator of traffic. The second measure is the flow centrality indicator $\left(C_{i}\right)$ that measures the airport's importance as a connecting point. As defined above, it is calculated as the ratio between connecting passengers $\left(c_{i}\right)$ and total network passengers that do not originate or terminate the $i$-th airport $\left(P-o d_{i}\right)$.

$$
O D_{i}=\frac{o d_{i}}{P} \quad C_{i}=\frac{c_{i}}{P-o d_{i}}
$$

These two indicators can be used to obtain a more detailed profile on the individual airports' hub characteristics and develop a typology of airports in the US. Furthermore, it is also possible to establish a link between these measures and the aggregated indicator currently used by the FAA. Since the FAA considers enplanements instead of passengers for their indicator, which actually shows the intention of the FAA of aggregating both dimensions into one indicator indicator, we just need to define the total number of enplanements in the network $(E)$ and the sum of all types of traffic $\left(o d_{i}+c_{i}\right)$ across all the airports. Note the multiple-counting of connecting passengers (which implies that $E>P$ ). Then, the FAA indicator $\left(F A A_{i}\right)$ is defined as the share of airport $i$ over the total number of enplanements.

$$
E=\sum_{i}\left(o d_{i}+c_{i}\right) \quad F A A_{i}=\frac{o d_{i}+c_{i}}{E}
$$

Therefore, we can establish the following relationship between the FAA indicator and the disaggregated ones:

$$
F A A_{i}=O D_{i} \frac{P}{E}+C_{i} \frac{\left(P-O D_{i}\right)}{E}
$$

Equation 7 will be used in Section 4.2 to map the different combinations of $O D_{i}$ and $C_{i}$ that lead to the bi-dimensional $F A A_{i}$ value. This is expected to show the pitfalls of the unidimensional FAA system for hub classification.

\subsection{Hierarchical clustering}


Our alternative classification criteria will be expressed as a set of threshold values for connectivity and traffic generation, determined by using agglomerative hierarchical clustering (AHC) $)^{4}$ on a cross-section of our airport sample for the year 2011. The resulting hierarchical classification is typically presented in a tree-like diagram (i.e. dendrogram) that provides a much more informative structure than the flat clusters obtained from other partitioning methods, such as $k$-means. Starting from a matrix of pair-wise distances between the individual objects, AHC performs a sequence of merge operations that produce additional clusters at new levels of aggregation and are governed by a predefined clustering strategy. This paper uses the complete-linkage algorithm, combined with a Euclidean distance metric. In this method, each step merges the nearest two clusters according to the farthest distance among their components, which leads to more compact aggrupations. Hierarchical methods do not require predefining the number of clusters, which can instead be identified by using a "tree-cutting" method. We employ the pseudo- $F$ coefficient that takes the ratio of betweencluster variance to within-cluster variance (Calinski and Harabasz, 1974). The edges of the resulting clusters are then used to define the thresholds of our new airport categories.

\section{Results and discussion}

\subsection{Benchmarking of connectivity and centrality indicators}

Table 2 shows the results of the de-hubbing sensitivity analysis, which vary widely across the four indicators. That illustrates the numerous ways in which centrality is measured and the impact of these conceptual differences on their characterization of airport connectivity. ${ }^{5}$ Unsurprisingly, degree centrality, which depends solely on the airport's number of connections without taking into account route density, is the indicator that shows the least variability. This is explained by the practice of de-hubbed carriers and alliances to keep a minimum service in order to prevent re-hubbing by rival alliances (Redondi et al., 2012). Weighted and un-weighted betweenness centrality are also highly dependent on the airports' geographical location and route structure (see Wang et al., 2011, for a similar effect in China), although results are much more erratic and unpredictable. While airports such as Cincinnati and Washington Reagan show the expected drop of centrality linked to the closure of direct air routes, it is difficult to explain why Pittsburgh, Colorado Springs or Nashville experienced an increase in betweenness centrality during their de-hubbing period. Contrary to the other indicators, flow centrality is the only indicator that clearly presents the expected negative signs in all cases.

In addition to Table 2, the lack of sensitivity of degree and betweenness indicators to airline de-hubbing is shown graphically in Figure 3, which shows the normalized results for the massively de-hubbed St Louis Airport (STL) over the whole sample period.

Furthermore, the value of flow centrality as a measure is not only limited to big changes in the in the network structure, as Rodríguez-Déniz et al. (2013) show, it also reacts well to punctual events, such as industrial actions, in which the flow of traffic is interrupted. It is also important to highlight that de-hubbed airports do not tend to recover after the airline

\footnotetext{
${ }^{4}$ General references to data clustering are Everitt et al. (2001) and Xu and Wunsch (2005).

${ }^{5}$ Time-series data was adjusted for seasonality.
} 
has completed the process, thus agreeing with the supply-side analysis by Redondi et al. (2012).

Hence, we can conclude that the direct relationship between the changes in the amount of connecting traffic and the changes in the flow centrality measure shows that this indicator is a sensitive measure of airport connectivity.

Table 2. Percentage loss of centrality for a selection of de-hubbing cases.

\begin{tabular}{|c|c|c|c|c|c|c|c|c|}
\hline $\begin{array}{c}\text { Start } \\
\text { Year } \\
\& \\
\text { Quarter }\end{array}$ & $\begin{array}{c}\text { End } \\
\text { Year } \\
\& \\
\text { Quarter }\end{array}$ & Airport & Hub carrier & Main cause & Degree & $B C$ & $W B C$ & $C_{i}$ \\
\hline $\begin{array}{c}2005 \\
\mathrm{Q} 4\end{array}$ & $\begin{array}{c}2010 \\
\text { Q4 }\end{array}$ & $\begin{array}{l}\text { Cincinnati } \\
(\mathrm{CVG})\end{array}$ & $\begin{array}{c}\text { Delta- } \\
\text { Northwest }\end{array}$ & Merger & $-16.62 \%$ & $-43.89 \%$ & $-35.92 \%$ & $-80.38 \%$ \\
\hline $\begin{array}{c}2005 \\
\mathrm{Q} 2\end{array}$ & $\begin{array}{c}2005 \\
\mathrm{Q} 4\end{array}$ & $\begin{array}{l}\text { New Orleans } \\
\text { (MSY) }\end{array}$ & - & $\begin{array}{l}\text { Hurricane } \\
\text { Katrina }\end{array}$ & $-19.36 \%$ & $-17.99 \%$ & $-40.66 \%$ & $-82.37 \%$ \\
\hline $\begin{array}{c}2001 \\
\mathrm{Q} 4\end{array}$ & $\begin{array}{c}2005 \\
\mathrm{Q} 1\end{array}$ & $\begin{array}{l}\text { Pittsburgh } \\
\text { (PIT) }\end{array}$ & US Airways & $\begin{array}{c}\text { Network } \\
\text { Restructuring } \\
\end{array}$ & $-5.89 \%$ & $13.93 \%$ & $-4.57 \%$ & $-77.91 \%$ \\
\hline $\begin{array}{c}2001 \\
\text { Q3 }\end{array}$ & $\begin{array}{c}2004 \\
\text { Q1 }\end{array}$ & $\begin{array}{l}\text { Saint Louis } \\
\text { (STL) }\end{array}$ & $\begin{array}{l}\text { American- } \\
\text { TWA }\end{array}$ & Merger & $-7.26 \%$ & $4.72 \%$ & $-9.22 \%$ & $-83.50 \%$ \\
\hline $\begin{array}{c}2001 \\
\text { Q3 }\end{array}$ & $\begin{array}{c}2001 \\
\mathrm{Q} 4\end{array}$ & $\begin{array}{l}\text { Reagan } \\
\text { (DCA) }\end{array}$ & US Airways & $\begin{array}{c}\text { 9/11 Security } \\
\text { Restrictions }\end{array}$ & $-6.99 \%$ & $-29.30 \%$ & $-11.84 \%$ & $-73.91 \%$ \\
\hline $\begin{array}{c}2001 \\
\text { Q2 }\end{array}$ & $\begin{array}{c}2001 \\
\mathrm{Q} 4\end{array}$ & $\begin{array}{l}\text { Raleigh-Durham } \\
\text { (RDU) }\end{array}$ & Midway & Bankruptcy & $-8.80 \%$ & $-38.56 \%$ & $-21.90 \%$ & $-81.55 \%$ \\
\hline $\begin{array}{c}1997 \\
\text { Q1 }\end{array}$ & $\begin{array}{c}1997 \\
\text { Q4 }\end{array}$ & $\begin{array}{c}\text { Colorado Springs } \\
\text { (COS) }\end{array}$ & $\begin{array}{l}\text { Western } \\
\text { Pacific }\end{array}$ & $\begin{array}{c}\text { Network } \\
\text { Restructuring } \\
\end{array}$ & $-5.29 \%$ & $-1.78 \%$ & $10.13 \%$ & $-77.74 \%$ \\
\hline $\begin{array}{c}1995 \\
\text { Q1 }\end{array}$ & $\begin{array}{c}1996 \\
\text { Q1 }\end{array}$ & $\begin{array}{c}\text { Nashville } \\
\text { (BNA) }\end{array}$ & American & $\begin{array}{c}\text { Network } \\
\text { Restructuring }\end{array}$ & $-2.89 \%$ & $25.11 \%$ & $0.90 \%$ & $-72.15 \%$ \\
\hline
\end{tabular}

Degree: Degree Centrality.

$B C$ : Un-weighted Betweenness Centrality.

WBC: Weighted Betweenness Centrality.

$C_{i}:$ Flow Centrality.

Note: De-hubbing periods were defined following Redondi et al. (2010) and direct examination of the time series data.

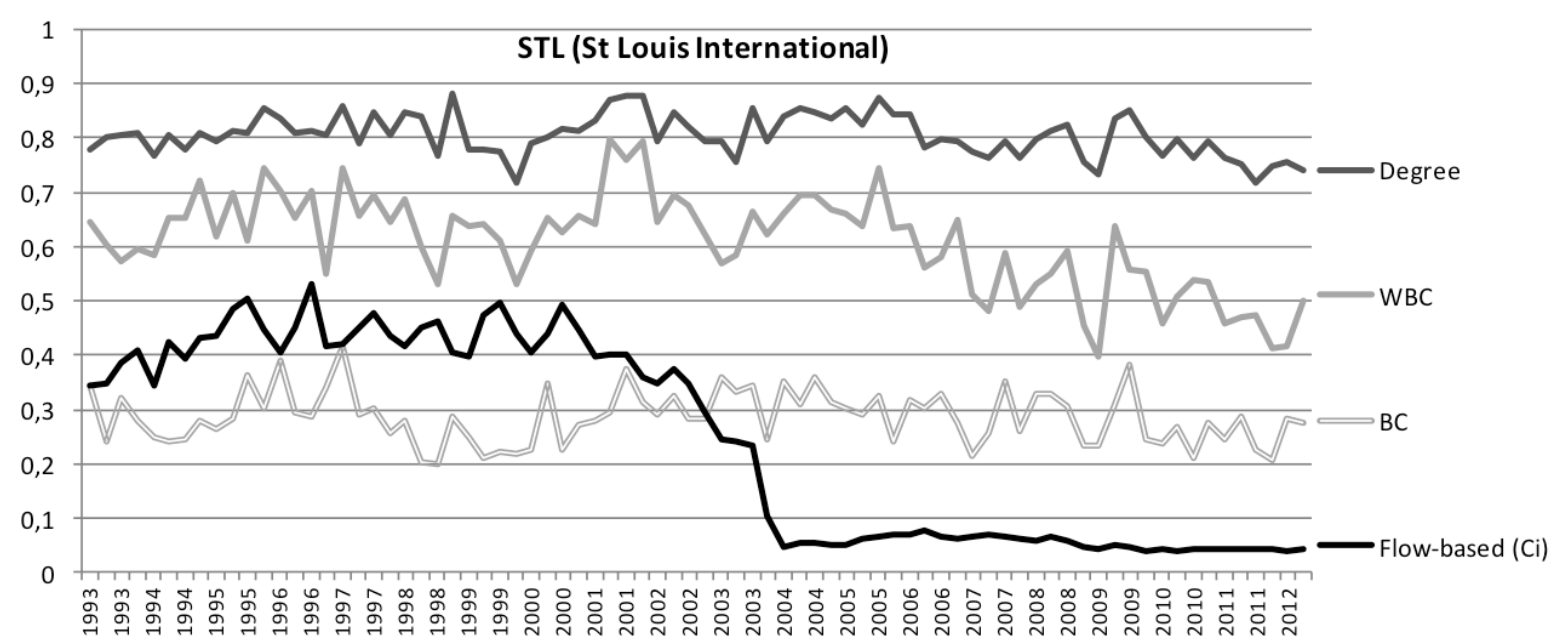

Figure 3. Evolution of centrality measures at St Louis International Airport (STL), 1993-

2012. 


\subsection{Classifying airports according to their hub dimensions: an application to the NPIAS}

Having tested the sensitivity of $C_{i}$, we can then proceed to calculate the traffic generation indicator $\left(O D_{i}\right)$, the flow centrality indicator $\left(C_{i}\right)$ and the aggregated FAA indicator $\left(F A A_{i}\right)$ for the whole sample. Table 3 and Figure 4 present the results on the two hub dimensions and the aggregated $F A A_{i}$ for all FAA-designated large (1\% or more) and medium hubs (between $0.25 \%$ and 1\%). Using Equation 10, we are also able to represent the different levels of the FAA indicator as a combination of connectivity and traffic generation. This graphical representation allows for a better comparison between both classification dimensions.

At first sight, we can conclude that the definition of a $1 \%$ share of enplanements as a threshold for large hubs is appropriate since it is located around a natural breaking point in the dataset. This is undoubtedly a first advantage of the FAA classification, and the second one is, evidently, its simplicity, as it only depends on a simple ratio. However, simplicity comes at the cost of discriminating power. All airports above 1\% are large hubs, but major differences in terms of generation and connectivity exist among them (Figure 4). For example, in the same category, the current FAA system mixes a mid-size hub (Charlotte Douglas-CLT) with a massive one (Atlanta-ATL), whose contribution to the network is twice as large in both dimensions, and both of them are joined by a massive traffic generator (Los Angeles-LAX). Thus, when aggregating both hub dimensions into a single indicator, the current FAA airport classification (Table 1) cannot discriminate among the different airports.

Table 3. Traffic generation and connectivity hub dimensions, and aggregated FAA indicator for medium and large hubs, 2011.

\begin{tabular}{|c|c|c|c|c|c|c|c|c|c|c|c|c|c|c|c|}
\hline & $O D i(\%)$ & $\mathrm{Ci}(\%)$ & $F A A i(\%)$ & & $O D i(\%)$ & $\mathrm{Ci}(\%)$ & $F A A i(\%)$ & & $O D i(\%)$ & $C i(\%)$ & $F A A i(\%)$ & & $O D i(\%)$ & $C i(\%)$ & $F A A i(\%)$ \\
\hline ATL & 5.60 & 5.70 & 4.64 & FLL & 4.00 & 0.09 & 1.73 & RDU & 1.76 & 0.05 & 0.77 & ONT & 1.02 & 0.02 & 0.44 \\
\hline ORD & 5.91 & 2.76 & 3.60 & EWR & 3.59 & 0.37 & 1.67 & SJC & 1.75 & 0.06 & 0.76 & OGG & 0.93 & 0.09 & 0.43 \\
\hline DEN & 5.78 & 2.81 & 3.57 & SAN & 3.46 & 0.12 & 1.51 & MSY & 1.75 & 0.05 & 0.76 & BUR & 1.00 & 0.02 & 0.43 \\
\hline LAX & 7.29 & 1.09 & 3.51 & DCA & 3.18 & 0.40 & 1.51 & MKE & 1.51 & 0.20 & 0.72 & PVD & 0.87 & 0.01 & 0.37 \\
\hline DFW & 4.78 & 3.06 & 3.26 & MDW & 2.60 & 0.84 & 1.45 & SAT & 1.64 & 0.04 & 0.71 & OMA & 0.85 & 0.02 & 0.36 \\
\hline LAS & 6.77 & 0.70 & 3.14 & TPA & 3.20 & 0.15 & 1.41 & PIT & 1.60 & 0.04 & 0.69 & RNO & 0.76 & 0.03 & 0.34 \\
\hline PHX & 4.84 & 1.90 & 2.82 & SLC & 2.19 & 0.99 & 1.34 & RSW & 1.60 & 0.01 & 0.68 & TUS & 0.76 & 0.02 & 0.33 \\
\hline $\mathrm{MCO}$ & 6.20 & 0.24 & 2.72 & PDX & 2.40 & 0.21 & 1.10 & DAL & 1.27 & 0.29 & 0.66 & ANC & 0.66 & 0.08 & 0.31 \\
\hline SFO & 5.43 & 0.63 & 2.55 & HNL & 2.27 & 0.28 & 1.08 & IND & 1.49 & 0.03 & 0.65 & $\mathrm{OKC}$ & 0.72 & 0.02 & 0.31 \\
\hline SEA & 4.66 & 0.75 & 2.28 & IAD & 1.91 & 0.61 & 1.06 & CLE & 1.21 & 0.29 & 0.63 & ORF & 0.67 & 0.01 & 0.29 \\
\hline BOS & 4.98 & 0.09 & 2.14 & MIA & 2.14 & 0.29 & 1.03 & SJU & 1.33 & 0.03 & 0.57 & SDF & 0.65 & 0.02 & 0.28 \\
\hline CLT & 2.04 & 2.98 & 2.10 & STL & 2.17 & 0.25 & 1.02 & $\mathrm{CMH}$ & 1.27 & 0.03 & 0.55 & RIC & 0.65 & 0.01 & 0.28 \\
\hline LGA & 4.67 & 0.20 & 2.05 & MCI & 1.96 & 0.12 & 0.88 & MEM & 0.70 & 0.59 & 0.55 & LGB & 0.64 & 0.02 & 0.28 \\
\hline MSP & 3.40 & 1.46 & 2.04 & OAK & 1.91 & 0.10 & 0.85 & PBI & 1.24 & 0.02 & 0.53 & GEG & 0.64 & 0.01 & 0.27 \\
\hline PHL & 3.53 & 1.10 & 1.94 & HOU & 1.65 & 0.31 & 0.83 & BDL & 1.19 & 0.01 & 0.51 & MHT & 0.62 & 0.00 & 0.26 \\
\hline DTW & 3.08 & 1.44 & 1.90 & SNA & 1.91 & 0.04 & 0.82 & JAX & 1.14 & 0.03 & 0.50 & ELP & 0.59 & 0.03 & 0.26 \\
\hline JFK & 3.95 & 0.31 & 1.80 & SMF & 1.87 & 0.06 & 0.82 & ABQ & 1.08 & 0.09 & 0.49 & BHM & 0.58 & 0.03 & 0.26 \\
\hline BWI & 3.60 & 0.67 & 1.80 & AUS & 1.82 & 0.06 & 0.80 & $\mathrm{CVG}$ & 0.85 & 0.27 & 0.47 & BOI & 0.58 & 0.02 & 0.25 \\
\hline IAH & 2.65 & 1.60 & 1.78 & BNA & 1.68 & 0.20 & 0.79 & BUF & 1.09 & 0.02 & 0.47 & TUL & 0.56 & 0.02 & 0.25 \\
\hline
\end{tabular}




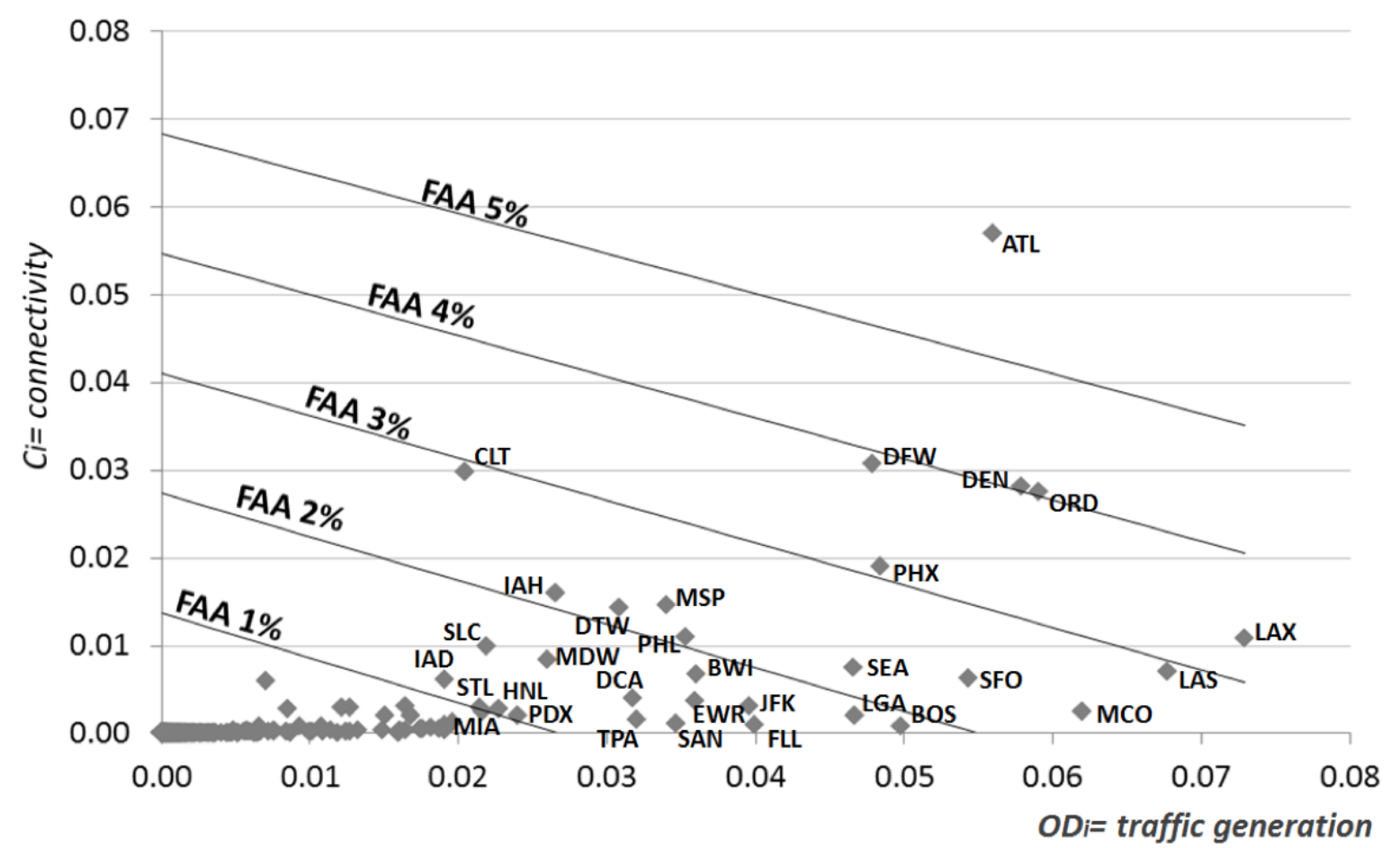

Figure 4. Disaggregated vs. FAA airport classification: large hubs (>1\%), 2011.

In order to obtain an alternative airport classification we use the agglomerative hierarchical clustering on the basis of the generation of traffic and the flow-based indicators. The results of the clustering are presented in Table 4, which have an optimal truncation level (similarity $=0.0182$ ) that leads to nine clusters. However, for simplicity, we decided to explore the dendrogram for the immediately next level of aggregation (0.03), leading to six clusters for easier interpretation (Figure 5).

Table 4. Class memberships and centroids for optimal truncation level.

\begin{tabular}{|c|c|c|c|c|c|c|c|c|c|c|c|c|}
\hline Class & 1 & 2 & 3 & 4 & 5 & 6 & 7 & \multicolumn{2}{|c|}{8} & \multicolumn{3}{|c|}{9} \\
\hline Objects & 1 & 4 & 2 & 5 & 1 & 3 & 8 & \multicolumn{2}{|c|}{22} & \multicolumn{3}{|c|}{30} \\
\hline Minimum distance to centroid & 0.000 & 0.005 & 0.003 & 0.004 & 0.000 & 0.001 & 0.000 & \multicolumn{2}{|c|}{0.001} & & 0.001 & \\
\hline Average distance to centroid & 0.000 & 0.007 & 0.003 & 0.006 & 0.000 & 0.003 & 0.004 & \multicolumn{2}{|c|}{0.003} & & 0.003 & \\
\hline Maximum distance to centroid & 0.000 & 0.009 & 0.003 & 0.010 & 0.000 & 0.004 & 0.007 & \multicolumn{2}{|c|}{0.009} & & 0.005 & \\
\hline \multirow[t]{11}{*}{ Class members } & \multirow[t]{11}{*}{ ATL } & ORD & LAX & $\mathrm{MCO}$ & CLT & MSP & PHL & MDW & SMF & DAL & ONT & $\mathrm{RIC}$ \\
\hline & & DEN & LAS & SFO & & DTW & JFK & SLC & AUS & CLE & OGG & LGB \\
\hline & & DFW & & SEA & & IAH & BWI & PDX & BNA & SJU & BUR & GEG \\
\hline & & PHX & & BOS & & & FLL & HNL & RDU & $\mathrm{CMH}$ & PVD & MHT \\
\hline & & & & LGA & & & EWR & IAD & SJC & MEM & OMA & ELP \\
\hline & & & & & & & SAN & MIA & MSY & PBI & RNO & BHM \\
\hline & & & & & & & DCA & STL & MKE & BDL & TUS & BOI \\
\hline & & & & & & & TPA & MCI & SAT & JAX & ANC & TUL \\
\hline & & & & & & & & OAK & PIT & ABQ & $\mathrm{OKC}$ & \\
\hline & & & & & & & & $\mathrm{HOU}$ & RSW & $\mathrm{CVG}$ & ORF & \\
\hline & & & & & & & & SNA & IND & BUF & $\mathrm{SDF}$ & \\
\hline Centroid & $A T L$ & $D E N$ & $L A S$ & SFO & $C L T$ & $D T W$ & $E \boldsymbol{W R}$ & & & & $O M A$ & \\
\hline OD-traffic generation & 0.056 & 0.058 & 0.068 & 0.054 & 0.020 & 0.031 & 0.036 & & & & 0.008 & \\
\hline C-connectivity & 0.057 & 0.028 & 0.007 & 0.006 & 0.030 & 0.014 & 0.004 & & & & 0.000 & \\
\hline
\end{tabular}




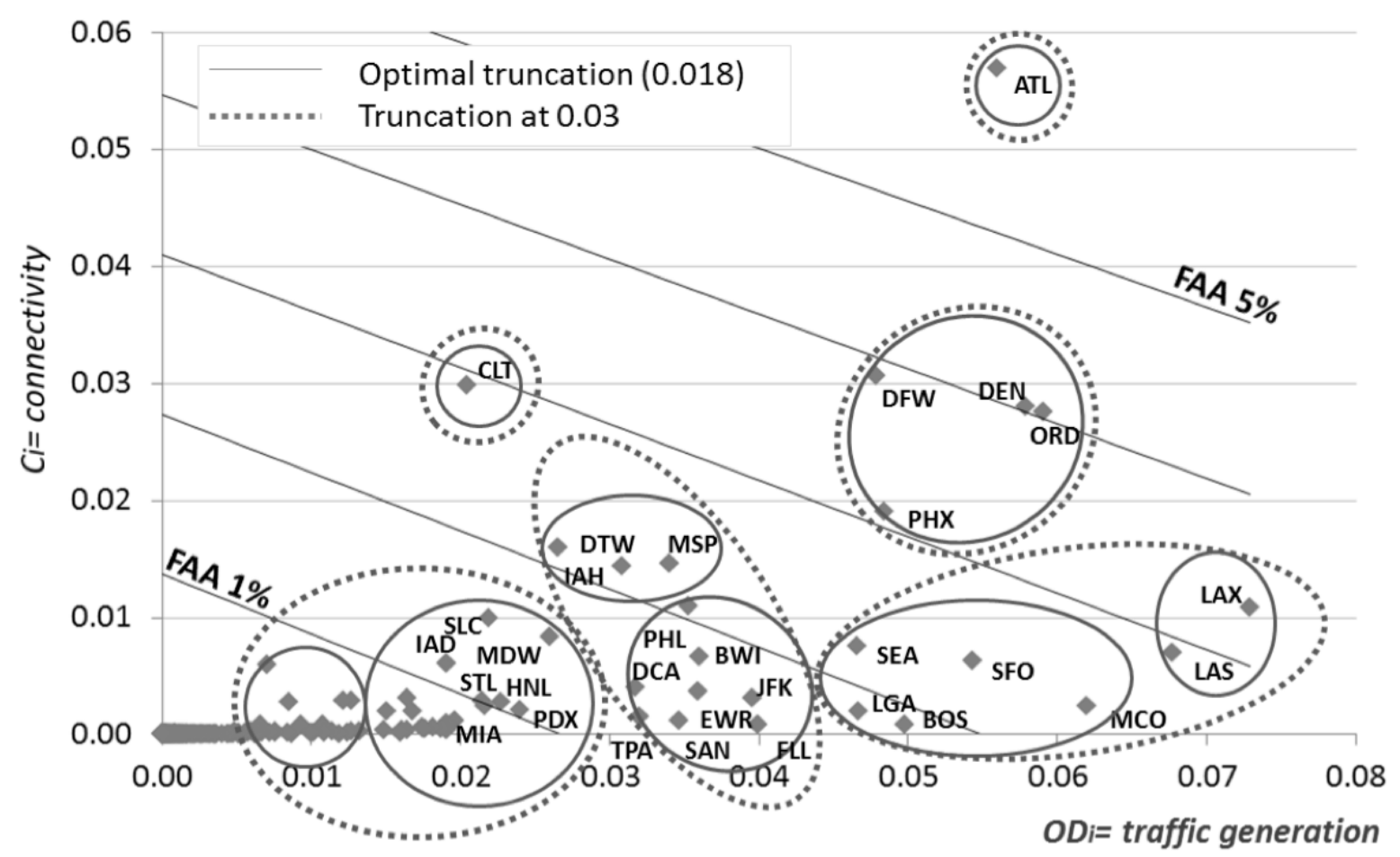

Figure 5. Class memberships at different truncation levels, 2011.

With this alternative classification, Atlanta Airport and Charlotte Douglas Airport would be placed in their own categories -first and third tier hubs respectively-, which is not surprising since there are no other airports that get close to their hub profiles. The remaining airports that score high in both dimensions, such as Dallas/Fort Worth (DFW) or Chicago O'Hare (ORD) are classified as second tier hubs. Simple criteria for belonging to these clusters are detailed in Table 5.

In addition to the hubs, this alternative classification has three additional groups for "traffic generators" (Table 5). In the first tier, we find the main airports serving the largest metropolitan areas in the US, for which a representative airport would be San Francisco (SFO). In the second tier are found airports such as Baltimore-Washington or Newark. The remaining airports are grouped in the third tier.

Table 5. Clusters criteria and representative airports.

\begin{tabular}{cccc}
\hline Hubs & Representative & OD\% & $\boldsymbol{C} \%$ \\
\hline $1^{\text {st }}$ tier & Atlanta & $>5 \%$ & $>5 \%$ \\
$2^{\text {nd }}$ tier & Denver & $>5 \%$ & $>2 \%$ \\
$3^{\text {rd }}$ tier & Charlotte & $>2 \%$ & $>2 \%$ \\
\hline Traffic generators & Representative & $\boldsymbol{O D} \%$ & $\boldsymbol{C} \%$ \\
\hline $1^{\text {st }}$ tier & San Francisco & $>5 \%$ & - \\
$2^{\text {nd }}$ tier & Baltimore-Washington & $>3 \%$ & - \\
$3^{\text {rd }}$ tier & Oakland & $>1 \%$ & - \\
\hline
\end{tabular}

Hence, Table 5 summarizes the alternative classification for regulatory purposes. The values are based on the edges of the cluster described above. It is worth highlighting the 
simplicity and similarity with the current FAA method, the availability of the data to perform the calculations, and its ready applicability.

Nevertheless, it is important to acknowledge limitation that rises from the dataset. Note the odd location of large international gateways such as New York-JFK, Miami (MIA) or Washington-Dulles (IAD), which show low levels of connectivity. It seems difficult to justify that these important airports are classified as second or third tier traffic generators. Clearly, this is related to the absence of international markets in the BTS dataset. As a result, all these large gateways are characterized here only by their contribution to domestic markets. We believe that this issue could be overcome by using supply data followed by correction algorithms, yet this remains out of the scope of this paper and does not invalidate its main contributions. These are the flow centrality measure and the alternative airport classification, which can be updated when the appropriate data becomes available. In addition, gateways are easily identifiable by their substantial amount of international passengers and their dominant position within the network of international connections (Figure 6). They tend to be located in large urban regions and have a more stable traffic since they often have emerged at the convergence on inland transport systems (Rodrigue et al., 2006), while other hubs can disappear if the carrier withdraws the services.

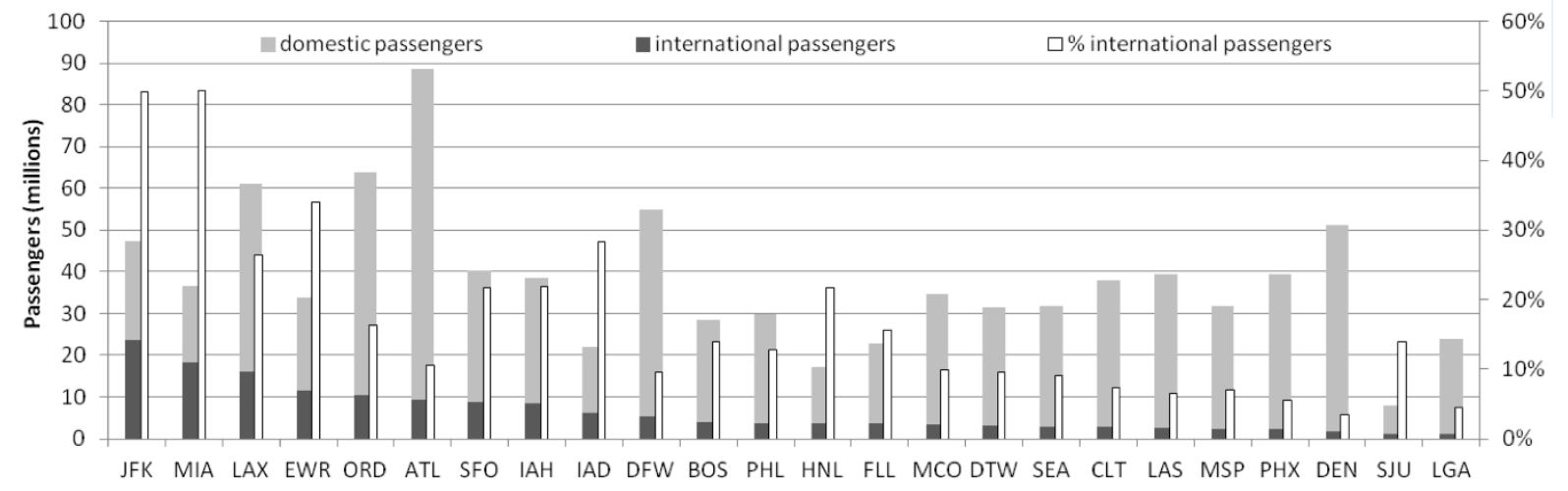

Figure 6. Largest international gateways in the US. Source: Own elaboration from the Bureau of Transport Statistics.

\section{Conclusions}

In summary, this paper develops an alternative airport classification method within the context of the Federal Aviation Administration's National Plan of Integrated Airport Systems (NPIAS). A bi-dimensional classification is proposed, considering both traffic generation and connectivity, since the uni-dimensional classification criteria proposed by the FAA is shown to be insufficient to characterize the hub profiles of the different airports.

A flow centrality indicator of airport connectivity has been constructed. It is shown to be much more sensitive to airline de-hubbing than other indicators that have been used in the same context such as degree centrality and betweenness centrality. This is related to the fact that these topological measures only take into account the number of established traffic links without considering the density of traffic flows. Thus, we conclude that flow-based centrality could be used as the standard demand-based indicator to measure actual airport connectivity. 
From the policy perspective, the suitability of this indicator to serve as a criterion for airport classification in the US domestic network was discussed. The major requirement for the regulator would be to set the thresholds that define the airport categories, which can be easily obtained using data clustering techniques, such as the we have used.

From a methodological point of view, further research could try to investigate ways to cover the limitations on the availability of international demand data. This might be overcome by using supply data followed by correction algorithms. From an analysis point of view, further research could focus on applying the flow-based indicator to do much in-depth demand-based analysis of airline de-hubbing cases and, in particular, on the variables that have an impact on airport recovery. Also, with regard to the airport clustering methods, there is scope for more studies looking into the usefulness of this method for the definition of policies and regulatory norms, as well as airport performance evaluation.

\section{Acknowledgements}

The authors would like to thank $\mathrm{SAS}^{\circledR}$ Institute for the support provided during the early stages of this work through the SAS ${ }^{\circledR}$ Student Ambassador Program.

\section{References}

Adikariwattage, V., de Barros, A.G., Wirasinghe, S.S., Ruwanpura, J., 2012. Airport classification criteria based on passenger characteristics and terminal size. Journal of Air Transport Management 24, 36-41.

Bhadra, D., 2009. Race to the bottom or swimming upstream: performance analysis of US airlines. Journal of Air Transport Management 15, 227-235.

Bootsma, P. D., 1997. Airline flight schedule development; analysis and design tools for European hinterland hubs. PhD thesis, University of Twente, Utrecht.

Burghouwt, G., Hakfoort, J., 2001. The evolution of the European aviation network, 19901998. Journal of Air Transport Management 7, 311-318.

Burghouwt, G., 2007. Airline network development in Europe and its implications for airport planning. Aldershot, Ashgate.

Burghouwt, G., Redondi, R., 2013. Connectivity in Air Transport Networks. An Assessement of Models and Applications. Journal of Transport Economics and Policy 47, 35-53.

Button, K., 2002. Debunking some common myths about airport hubs. Journal of Air Transport Management 8, 177-188.

Calinski, T., Harabasz, J. 1974. A dendrite method for cluster analysis. Communications in Statistics 3, 1-27.

Dennis, N. P., 1994. Scheduling strategies for airline hub operations. Journal of Air Transport Management, 1(2), 131-44.

Doganis, R., 2010. Flying off course: the economics of international airlines ( $4^{\text {th }}$ Ed.). Routledge. London.

Doganis, R., N. Dennis, 1989. Lessons in hubbing. Airline Business, March 1989, $42-7$.

Everitt, B., Landau, S., Leese, M., 2001. Cluster Analysis 4th ed. Wiley, London.

FAA, 2011. Federal Aviation Administration National Plan of Integrated Airport System

(NPIAS) 2011-2015 Report. [online]

http://www.faa.gov/airports/planning_capacity/npias/reports/ 
Freeman, L., 1977. A set of measures of centrality based on betweenness. Sociometry 40, 3541.

Freeman, L., 1978. Centrality in social networks: Conceptual clarification. Social Networks 1, 215-239.

Freeman, L., Borgatti, S., White, R., 1991. Centrality in valued graphs: a measure of betweenness based on network flow. Social Networks 13, 141-154.

Galle, K., Ale, J., Hossain, M., Moliterno, M., Rowell, M., Revenko, N., Rogerson, E., Tucker, S., Crowther, K., Lambert, J., Haimes, Y., 2010. Risk-based airport selection for runway safety assessments through the development and application of systems-driven prioritization methodologies. Proceedings of the 2010 IEEE Systems and Information Engineering Design Symposium, University of Virginia.

Guimerà , R., Mossa, S., Turtschi, A., and Amaral, L. A., 2005. The worldwide air transport network: anomalous centrality, community structure and cities' global roles'. Proceedings of the National Academy of Sciences 102(22), 7794-9.

Jessop, A., 2012. A decision aid for finding performance groups. Benchmarking: An International Journal 19 (3), 325-339

Jia, T., Jiang, B., 2012. Building and analyzing the US airport network based on en-route location information. Physica A 391, 4031-4042.

Liu, Z-J., Debbage, K., Blackburn, B., 2006. Location determinants of major US air passenger markets by metropolitan area. Journal of Air Transport Management 12, 331-341.

Madas, M., Zografos, K., 2008. Airport capacity vs. demand: Mismatch or mismanagement? Transportation Research A 42, 203-226.

Malighetti, P., Paleari, S., Redondi, R., 2008. Connectivity of the European airport network: 'Self-help hubbing' and business implications. Journal of Air Transport Management 14(2), 53-65.

Malighetti, P., Paleari, S., Redondi, R., 2009. Airport classification and functionality within the European network. Problems and Perspectives in Management 7, 183-196.

Nieminem, J., 1974. On centrality in a graph. Scandinavian Journal of Psychology 15, 322336.

Oum, T.H., Zhang, A., Zhang, Y., 1995. Airline network rivality. Journal of Economics 18, 836-857.

Paleari, S., Redondi, R., Malighetti, P., 2010. A comparative study of airport connectivity in China, Europe and US: which network provides the best service to passengers?. Transportation Research E 46(2), 198-210.

Redondi, R., Malighetti, P., Paleari, S., 2010. De-hubbing of airports and their recovery patterns. Proceedings of the $14^{\text {th }}$ Air Transport Research Society. July 2010, Porto, Portugal.

Redondi, R., Malighetti, P., Paleari, S., 2012. De-hubbing of airports and their recovery patterns. Journal of Air Transport Management 18, 1-4.

RITA, 2013. Airline Origin and Destination Survey DB1B. Research and Innovative Technology Administration. US Bureau of Transportation Statistics, Washington DC. URL: http://www.rita.dot.gov/bts/data_and_statistics/index.html

Rodrigue, J-P., Comtois, C., Slack, B., 2006. The Geography of Transport Systems. Oxton, Routledge. Second Edition. 
Rodríguez-Déniz, H., 2012. Using SAS ${ }^{\circledR}$ to Measure Airport Connectivity: An Application of Weighted Betweenness Centrality for the FAA National Plan of Integrated Airport Systems (NPIAS). Proceedings of the SAS Global Forum 2012, Paper 162-2012.

Rodríguez-Déniz, H., Suau-Sanchez, P., Voltes-Dorta, A., 2013. Using SAS ${ }^{\circledR}$ to Measures Airport Connectivity: An Analysis of Airport Centrality in the US Network with SAS-IML ${ }^{\mathbb{R}}$ Studio. Proceedings of the SAS Global Forum 2013, Paper 152-2013.

Rodríguez-Déniz, H., Voltes-Dorta, A. 2014. A frontier-based hierarchical clustering for airport efficiency benchmarking. Benchmarking: an international journal. Article in Press.

Sarkis, J., and Talluri, S., 2004. Performance based clustering for benchmarking of US airports. Transportation Research A 38, 329-346.

Veldhuis, J., 1997. The competitive position of airline networks. Journal of Air Transport Management 3(4), 181-8.

Wang, J., Mo, H., Wang, F., Jin., F., 2011. Exploring the network structure and nodal centrality of China's air transport network: a complex network approach. Journal of Transport Geography 19, 712-721.

Xu, Z., Harriss, R., 2008. Exploring the structure of the U.S. intercity passenger air transportation network: a weighted complex network approach. Geo Journal 73, 87-102.

$\mathrm{Xu}, \mathrm{R}$, Wunsch, D., 2005. Survey of Clustering Algorithms. IEEE Transactions on Neural Networks 16 (3), 645-678. 
2013-11-09

\section{Classifying airports according to their hub dimensions: an application to the US domestic network}

\section{Rodríguez-Déniz, Héctor}

\section{Elsevier}

Héctor Rodríguez-Déniz, Pere Suau-Sanchez, Augusto Voltes-Dorta, Classifying airports according to their hub dimensions: an application to the US domestic network, Journal of Transport Geography, Volume 33, December 2013, pp188-195

http://dx.doi.org/10.1016/j.jtrangeo.2013.10.011

Downloaded from Cranfield Library Services E-Repository 